\title{
Posterior Portion of the Urethra
}

National Cancer Institute

\section{Source}

National Cancer Institute. Posterior Portion of the Urethra. NCI Thesaurus. Code C61126.

The portion of the urethra that is located on the posterior aspect of the urogenital diaphragm. 